\title{
Modeling and Simulation of a Large Chipper Drive
}

\author{
Christian Kral*, Anton Haumer, Hansjörg Kapeller and Gert Pascoli
}

Austrian Institute of Technology, Mobility Department, Giefinggasse 2, 1210 Vienna, Austria

\begin{abstract}
This paper presents a simulation model for a large chipper drive used in a paper mill. If the chipper drive is a slip ring induction motor, several advantages arise from using a rheostat in the rotor circuit. This paper will investigate the impact of a rotor circuit rheostat with respect to starting behavior and heavy duty load impulses. The chipper drive is modeled in Modelica, an object oriented multi domain simulation language. In addition to the theory, a practical case is presented to demonstrate the applicability of the derived knowledge.
\end{abstract}

Keywords: Chipper drive, slip ring induction motor, wound rotor induction machine, load impulses, simulation model, measurement results

\section{INTRODUCTION}

In a paper mill chipper drives are used to crush trunks for making wood chips. The nominal power of a motor used for such application ranges from several $100 \mathrm{~kW}$ up to $1 \mathrm{MW}$ and even more. Such a chipper drive is usually not operated continuously, because load impulse arise only if a trunk is shredded. After that, the motor is not loaded until the next trunk is processed. The load cycle of such a chipper drive is therefore heavy duty operation.

Starting the chipper drive causes large starting currents if no measures are taken. Under some circumstances, the chipper drive even has to start with some remaining parts of a trunk loaded which is a severe loading for the motor. For the motor not being supplied by an inverter, high starting currents arise from the low locked rotor impedance of the induction motor [1]. It is therefore often useful to use a slip ring motor instead of squirrel cage motor. With a slip ring motor an additional rheostat in the rotor circuit can be used to increase the starting impedance. This gives rise to reduced starting currents and improves the torque speed characteristic.

The heavy duty load impulses give rise to large motor currents which cause large voltage drops across the mains impedance. This leads, therefore, to voltage sags and flicker effects. To the regulations of the standards, and the actual configuration and structure of the voltage supply, certain voltage drops may not be exceeded during starting and impulse load operation. A rheostat in the rotor circuit can therefore also be used for diminishing the reactions of the load impulses on the motor currents and voltage sags.

The rheostat used in the rotor circuit of a slip ring induction motor are usually of the following types:

- Three phase (water) electrolyte based rheostats Depending on the design of the rheostat water may evaporate due to the heat losses at higher operating temperatures. In this case water has to be refilled

*Address correspondence to this author at the Arsenal Research, Mobility Department, Giefinggasse 2, 1210 Vienna, Austria; E-mail: christian.kral@ait.ac.at regularly to provide a certain concentration of the electrolyte. In a closed design of a water based rheostat water is not evaporating. The base resistance of the water based rheostat can be controlled by the concentration of the electrolyte Fig. (1). The immersion depth of the electrodes, however, determines the actual resistance of the rheostat. Apart from that, electrolyte based rheostats are low-maintenance and have a long lifetime of at least two decades.

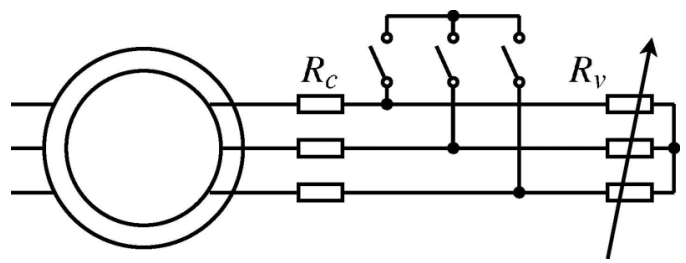

Fig. (1). Three phase rheostat of a slip ring induction motor.

- Three phase oil based rheostats - Oil based rheostats have a higher thermal capacitance than water based rheostats, which is advantageous. Due to the oil actually no maintenance is required. The main disadvantages of the oil based rheostat are that the base resistance is determined by the specific conductivity of the oil and can thus not be changed, higher production costs and the expensive disposal costs of the oil after putting the device out of service when the life time is exceeded.

- Single phase pulse controlled resistor - A three phase rectifier in the rotor circuit and a single phase pulse controlled resistor as shown in Fig. (2) can be used alternatively to a three phase device.

\section{SIMULATION MODEL}

The computer simulation of the chipper drive is performed with Modelica [2], which is an object oriented language for modeling systems through algebraic and ordinary differential equations. One of the main advantages of Modelica language is the acausal modeling of system equations. This way, each component of a system can be developed and tested independently. The object oriented 


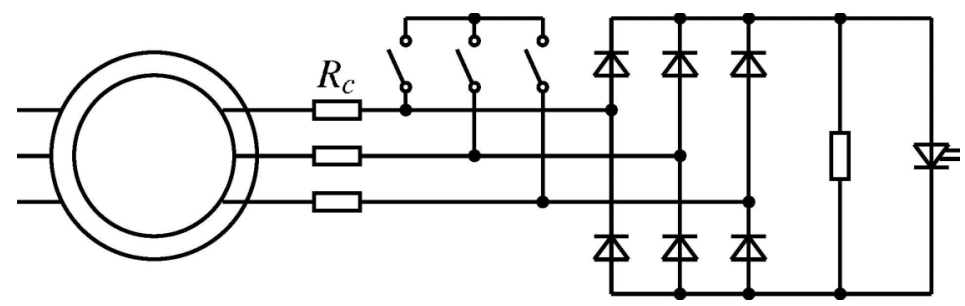

Fig. (2). Single phase pulse controlled resistor in the rotor circuit of a slip ring induction motor.

approach helps to unify model structures and to re-use code. The actual system equations of a complex physical system are determined by the boundary conditions and the connection of the components, not by the individual models. Since Modelica supports any kind of algebraic and ordinary differential equations, it is applicable to many engineering and physical domains. These domains comprise electrical, mechanical, thermal, control and mathematical systems.

The free Modelica Standard Library (MSL) provides a collection of standard components and component interfaces for many engineering domains. In the current version of the MSL all components for modeling the proposed chipper drive are offered. For the proposed simulation model mainly the MultiPhase, Machines and Rotational packages of the MSL are used.

In Fig. (3) the Modelica model of the investigated chipper drive is presented. The voltage supply is modeled by three sinusoidal supply voltages (sineVoltage) which are star (starG) connected. The overall mains impedance including all transmission lines and transformers, is modeled by a series connection of a three phase resistor (resistorG) and a three phase inductor (inductorG). For having the root mean square (RMS) values of the voltages and currents in the simulation results available, an RMS voltmeter and ampere meter are connected into the circuit. In addition to these instruments, a real and reactive power meter provides the characteristic power terms of the circuit. The stator winding of the slip ring induction motor (AIMS) is star connected, the stator terminals are connected with the mains impedances, incorporating the instruments for voltage, current and power measurement. The rotor circuit of the slip ring rotor is also star connected. The slip ring terminals are connected to a rheostat, which is modeled as a series connection of a constant resistor (resistorRe) and a variable resistor (variableResistor). In the simulation model depicted

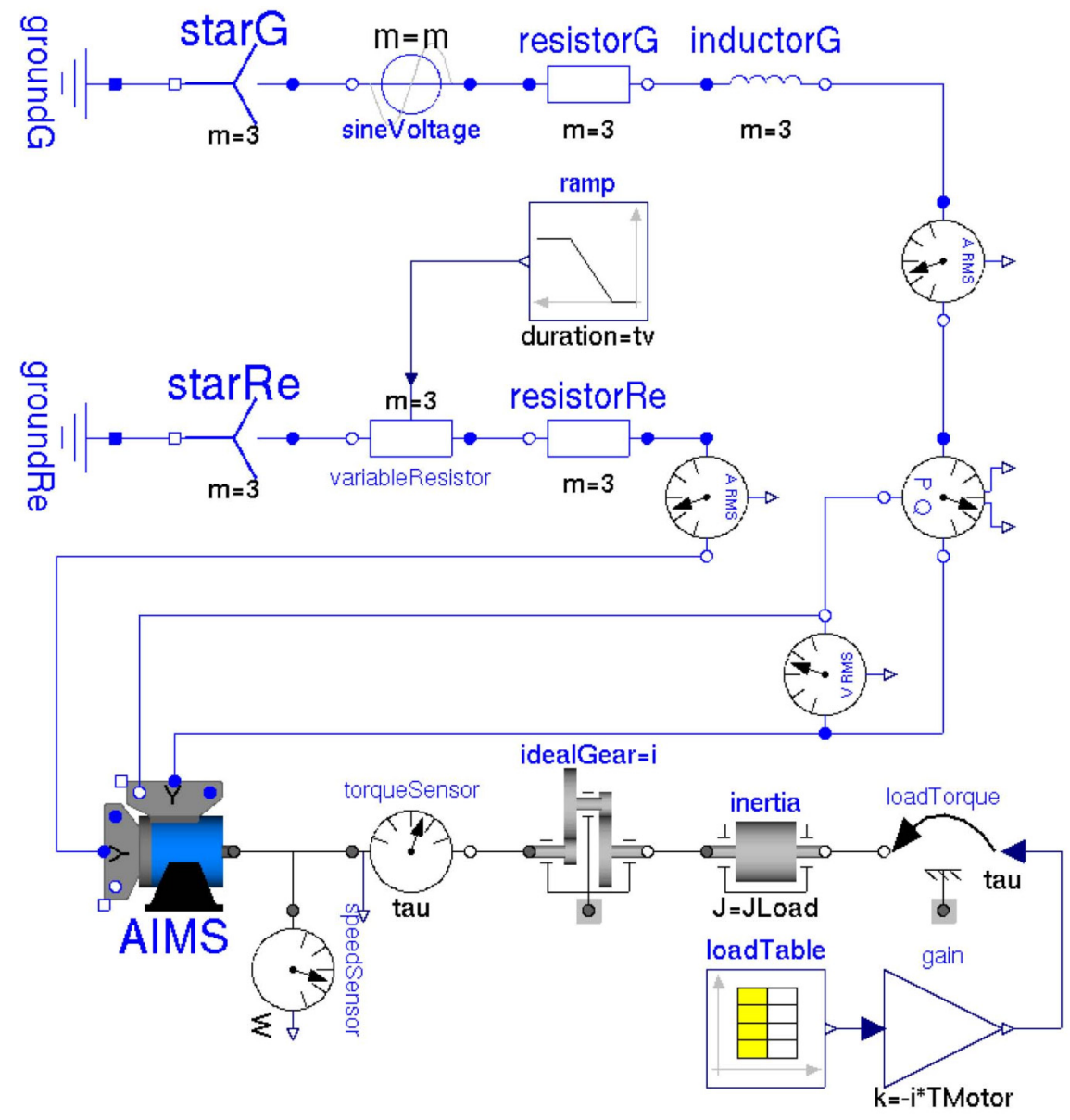

Fig. (3). Modelica model of a chipper drive. 
in Fig. (3) the variable resistor is controlled by a time table during the start-up of the motor. The signal inputs of the variable resistor, however, can be controlled by any other strategy as well. The mechanical shaft of the induction motor is connected with a torque and speed sensor. The power is transmitted through a gear (idealGear) to the load torque (loadTorque) model. The signal input of the load torque model is supplied by a time table (loadTable) modeling impulse loads. Since the extended cutting edges have a large diameter and thus inertia (inertia), the effective inertia of the drive with respect to the motor side is much higher than the inertia of the slip ring rotor.

\section{STATIONARY CHARACTERISTICS}

The single phase equivalent circuit of a slip ring induction motor is depicted in Fig. (4). In this equivalent circuit $R_{s}$ is the stator resistance, $X_{s \sigma}$ is the stator leakage inductance, $X_{m}$ is the magnetizing inductance, $X_{r \sigma}$ is the rotor

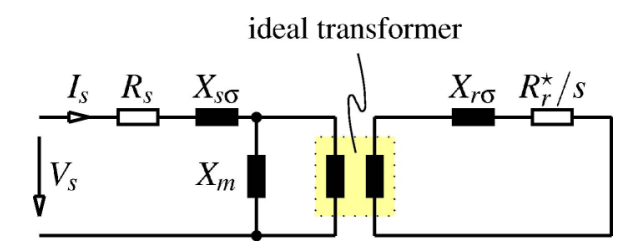

Fig. (4). Single phase equivalent circuit of a slip ring induction motor.

leakage reactance, $R_{r}^{*}$ is the total rotor resistance, $s$ is slip, $V_{s}$ is the stator phase voltage and $I_{s}$ is the stator phase current. The total rotor circuit resistance model to be investigated consists of three components, the actual rotor (winding) resistance $R_{r}$, and the variable resistance of the rheostat $R_{v}$ and an external constant resistance $R_{c}$. The total rotor circuit resistance is:

$R_{r}^{*}=R_{r}+R_{v}+R_{c}$

The stationary torque speed and the stationary current speed characteristic of a slip ring induction motor are shown in Fig. (5). The performed results refer to a $1.5 \mathrm{MW}$ four pole induction motor with a nominal line-to-line voltage of 6

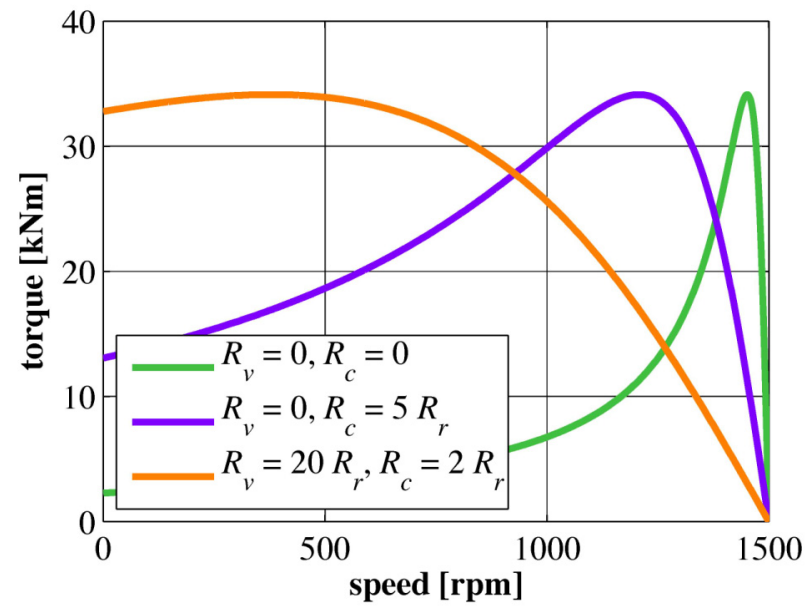

(a) Torque versus speed

Fig. (5). Stationary characteristics of a slip ring induction maching.
$\mathrm{kW}$ and a nominal phase current of $165 \mathrm{~A}$. For a short circuited rotor circuit $\left(R_{r}^{*}=R_{r}\right)$ the torque speed characteristic shows a very low starting torque and a starting current of approximately 7 times the nominal current. Yet, the stationary characteristics with rheostat for $R_{r}^{*}=23 R_{r}$ show a big improvement. In this case the locked rotor torque equals approximately the breakdown torque and the locked rotor current is less than 5.5 times the nominal current.

\section{TRANSIENT MOTOR START-UP}

For starting the chipper drive several control strategies of the rheostat can be applied:

- Time dependent control - The resistance of the rheostat is reduced along a linear ramp:

$R_{v}=R_{v, \max }\left(1-\frac{t}{t_{v}}\right)$

The duration of the ramp, $t_{v}$, has to be chosen according to the the actual inertia and starting conditions of drive. If the duration of the ramp, $t_{v}$, is adapted such way, that the motor shows optimal acceleration during an unloaded start-up, an arbitrary load torque due to remaining parts of a trunk may cause worse starting conditions and even higher starting currents.

- Stator current control - The resistance of the rheostat is controlled such way that the stator current does not exceed a certain limit, $I_{s, \max }$. Due to the control of the stator current, the starting current and torque are independent of the load torque during start-up. The control technique, however, has to be implemented in a programmable logic control (PLC), where the measured stator currents are acquired.

- $\quad$ Speed control - A speed controlled rotor circuit resistance also provides start-up torque and currents independent of the actual load conditions and is yet easy to implement in a PLC. Since speed sensors may be undesired in a drive applications, speed

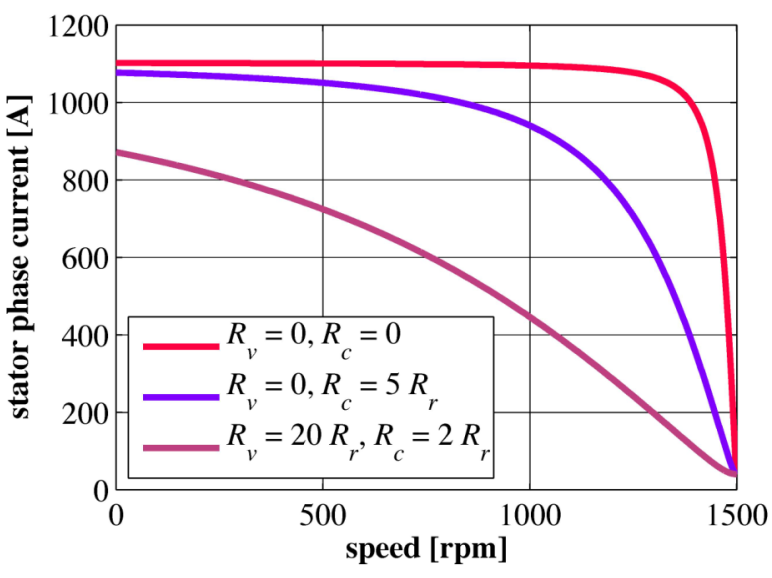

(b) Star current versus speed 
control may not be possible in a practical applications.

- Rotor current control - The resistance of the rheostat is controlled such way that the rotor current does not exceed a certain limit, $I_{r \text {, max }}$.

Simulation results for time dependent control of the resistance of the rheostat is depicted in Figs. (6-8). In the presented results $R_{v, \max }=20 R_{r}$ and $R_{c}=2 R_{r}$ were set. The duration of the linear ramp for decreasing the resistance of the rheostat is, $T=10 \mathrm{~s}$. Fig. (8) shows, that the motor is able to accelerate up to nominal speed within these $10 \mathrm{~s}$, whereas the short circuited slip ring rotor gives rise a start-up time of approximately $50 \mathrm{~s}$.

\section{TRANSIENT IMPULSE LOADS}

During the start-up of the chipper drive, the total rotor circuit resistance (1) determines the load speed characteristic as shown in Fig. (5). After reaching nominal speed, the variable resistance, $R_{v}$, is short circuited. According to Figs. (1-2), the external rotor circuit resistance is then determined by the constant resistance $R_{c}$.

If the motor is not loaded, the resistance $R_{c}$ does not have a significant influence on the motor current and speed. If the

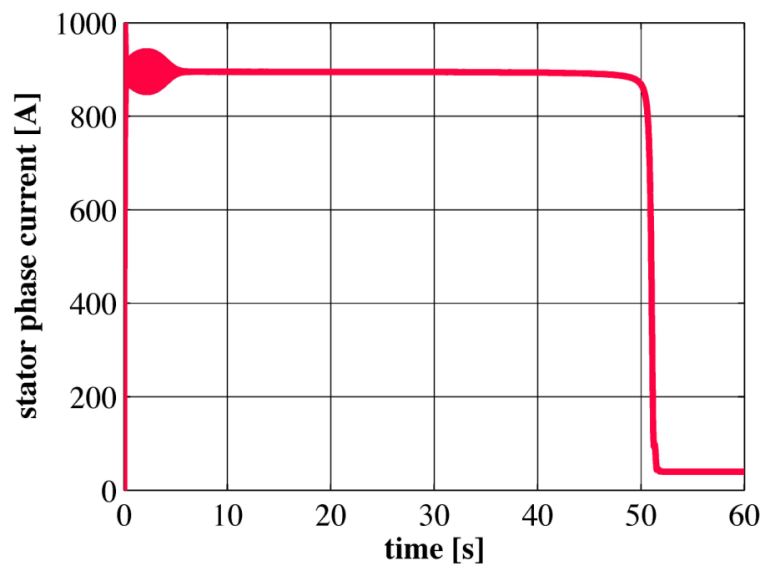

(a) Startup without rheostat

Fig. (6). Stator phase current during start-up of the unloaded chipper drive.

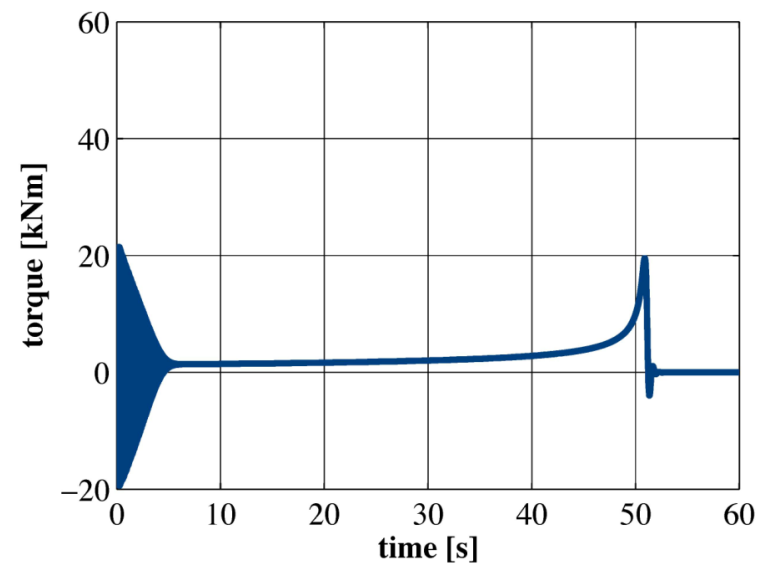

(a) Startup without rheostat

Fig. (7). Torque during start-up of the unloaded chipper drive. motor were loaded with a constant load torque, $T$, the stationary speed depends on the actual resistance $R_{c}$ according to

$\frac{R_{r}}{s}=\frac{R_{r}+R_{c}}{s_{c}}$.

In this equation, $s$ is the slip for the case without external rotor circuit resistance, and $s_{c}$ is the slip for the case with the external rotor circuit resistance $R_{c}$. The slip relation (3) is determined by the stationary equations given by Fig. (4). According to (3) larger external rotor circuit resistances $R_{c}$ lead to a larger slip $s_{c}>s$, and therefore, to a lower speed.

For a real chipper drive the loading is not continuously. The trunks are processed one after another, with certain intermissions of loading in between. The processing of the trunks can be approximated by load impulses of a certain duration. In a real application the peak torque will exceed the nominal load torque of the induction motor, however. Yet the average loading is expected to be much smaller than the nominal load.

When the load impulses occur, the motor is in transient operation and (3) cannot be applied. The modeled impulses have the waveform of Fig. (9). The characteristic parameters

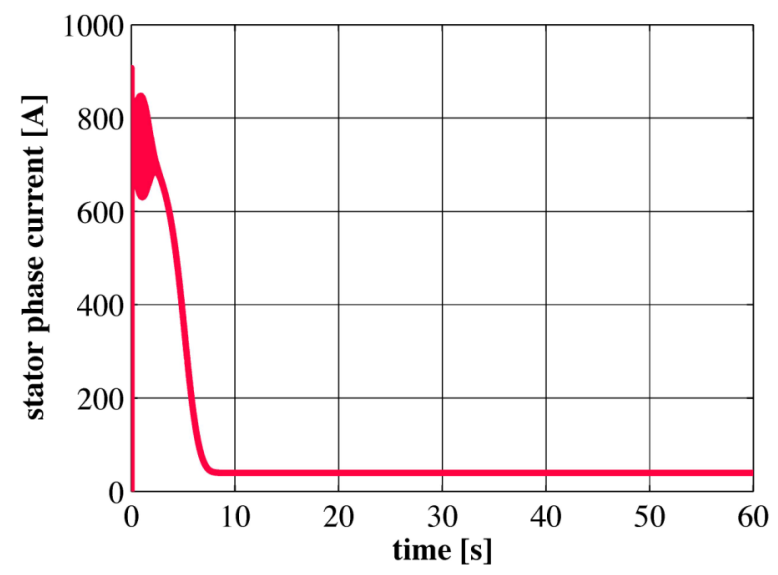

(b) Startup with $R_{v}=20 R_{r}$ and $R_{c}=2 R_{r}$

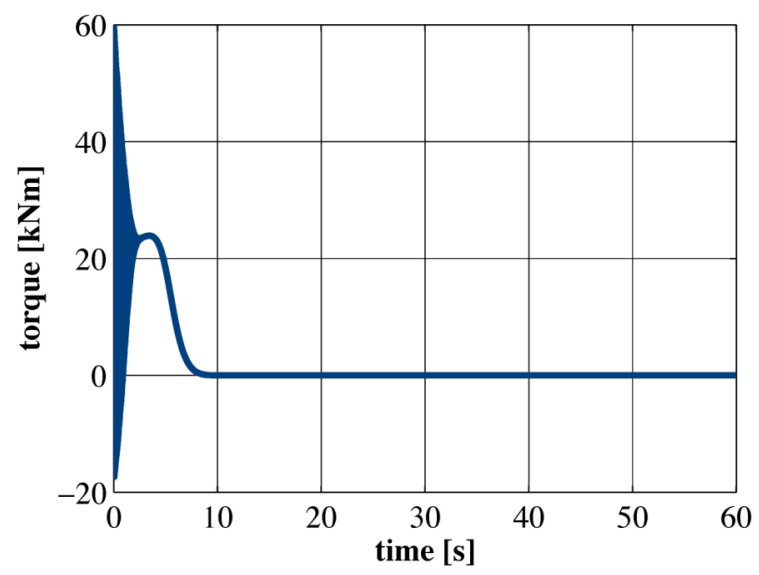

(b) Startup with $R_{v}=20 R_{r}$ and $R_{c}=2 R_{r}$. 


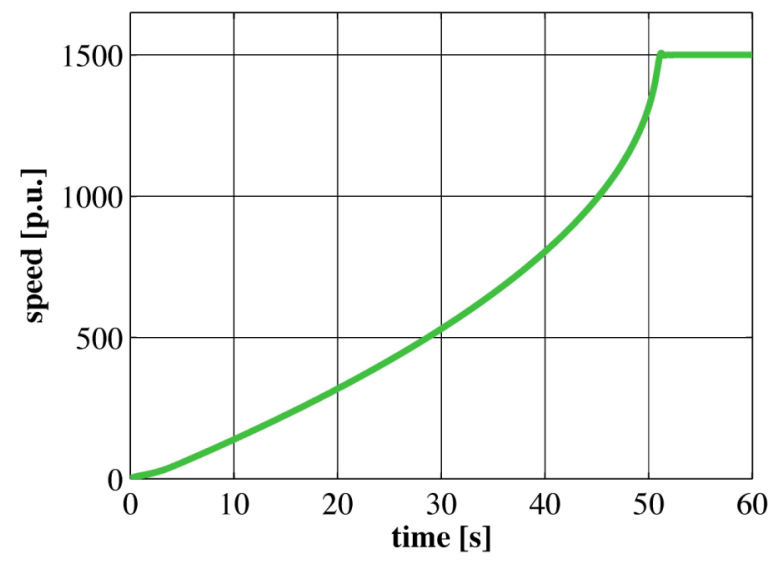

(a) Startup without rheostat

Fig. (8). Speed during start-up of the unloaded chipper drive.

of an impulse are the duration $\Delta t$, the rise time $t_{r}$, the fall time $t_{f}$ and the amplitude $\hat{T}$. In the presented simulation two load impulses are investigated. Each load impulse has equal rise and fall times, and the torque amplitude is twice the

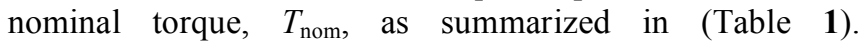
Simulation results with respect to the two investigated load impulses are shown in Figs. (10-12). The first impulse start at $t=0$, the second impulse starts at $t=10 \mathrm{~s}$.

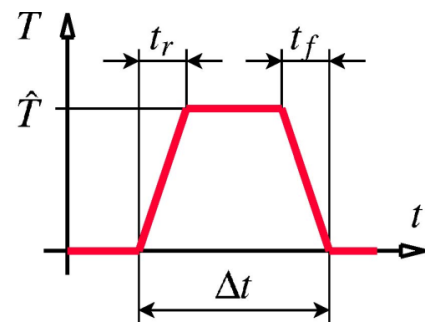

Fig. (9). Wave form of the modeled load impulse.

During the load impulses motor speed decreases, and yet stationary speed determined by (3) may not be reached. How close the stationary speed is approached during the transient reaction of the motor, is mainly determined by the total inertia of the drive, $J$, the external rotor circuit resistance, $R_{c}$, and the length $\Delta t$ of the torque impulse. A larger external

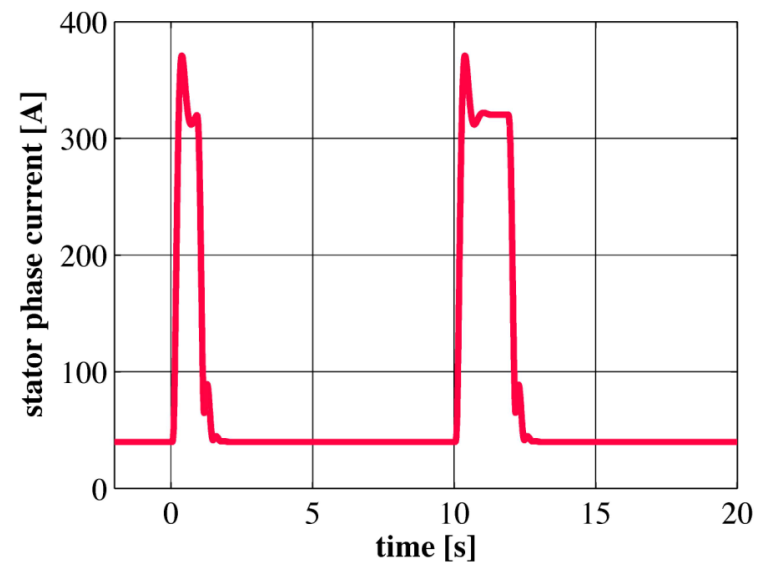

(a) Load impulses without rheostat, $R_{c}=0$

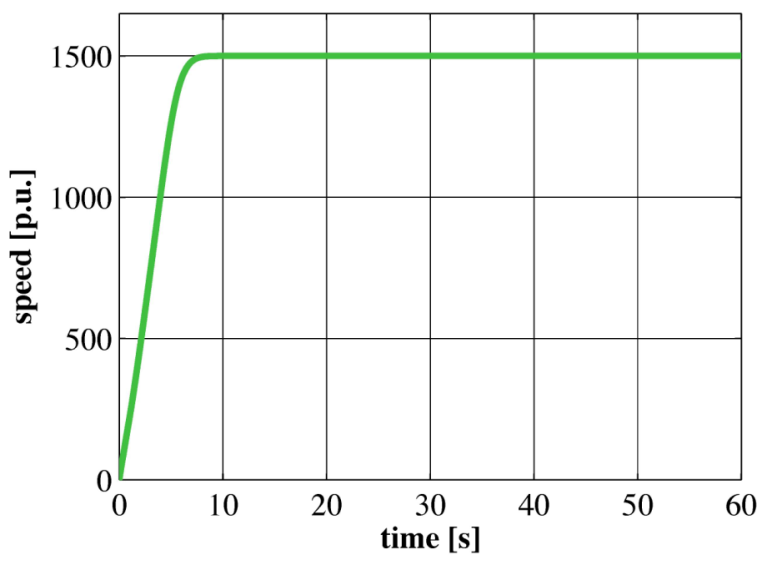

(b) Startup with $R_{v}=20 R_{r}$ and $R_{c}=2 R_{r}$

rotor circuit resistance leads to larger speed dip, as shown in Fig. (12). This circumstance is advantageous, since a larger speed dip gives rise to a more prominent attenuation effect due to the kinetic energy. If $\Omega_{m, 0}$ designates synchronous speed of the motor and $\Omega_{m, \min }$ is the minimum of the speed dip, the kinetic energy provided from the drive inertia is

$\Delta E=\frac{J}{2}\left(\Omega_{m, 0}^{2}-\Omega_{m, \min }^{2}\right)$.

Table 1. Characteristic Data of the Load Impulses

\begin{tabular}{|c|c|c|c|c|}
\hline \# impulse & $\boldsymbol{t}_{\boldsymbol{r}}$ & $\boldsymbol{t}_{\boldsymbol{f}}$ & $\boldsymbol{\Delta}_{\boldsymbol{t}}$ & $\hat{\boldsymbol{T}} / \boldsymbol{T}_{\text {nom }}$ \\
\hline \hline & {$[\mathrm{s}]$} & {$[\mathrm{s}]$} & {$[\mathrm{s}]$} & \\
\hline 1 & 0.1 & 0.1 & 1 & 2 \\
\hline 2 & 0.1 & 0.1 & 2 & 2 \\
\hline
\end{tabular}

A larger external rotor circuit resistance $R_{c}$ gives also rise to a smaller stator (and rotor) current peak and a smaller electrical torque peak as shown in Figs. (10-11). An additional effect is, that the transient time constant is increases with the external rotor resistance.

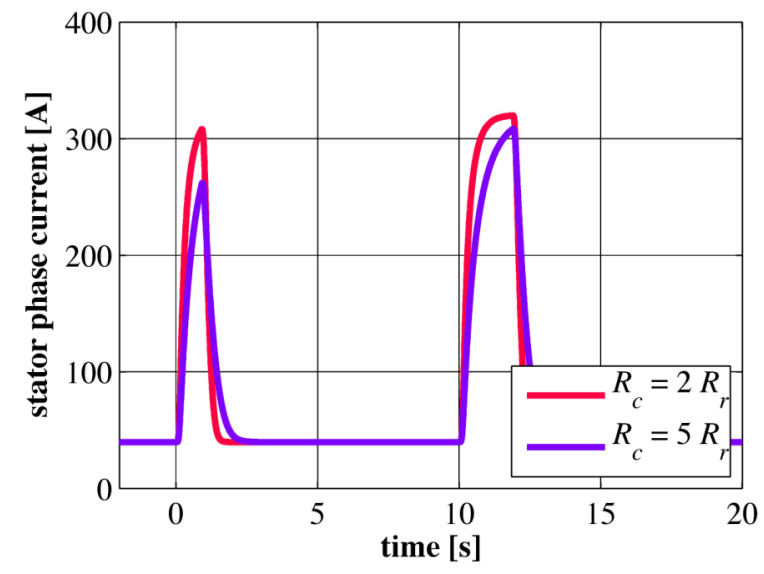

(b) Load impulses with $R_{c}=2 R_{r}$ and $R_{c}=5 R_{r}$

Fig. (10). Stator phase current during periodic loading of the chipper drive. 


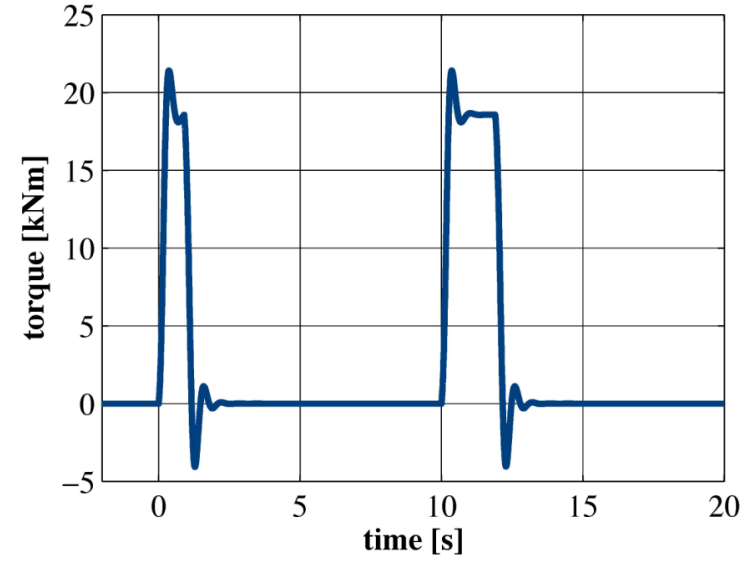

(a) Load impulses without rheostat, $R_{c}=0$

Fig. (11). Torque during periodic loading of the chipper drive.

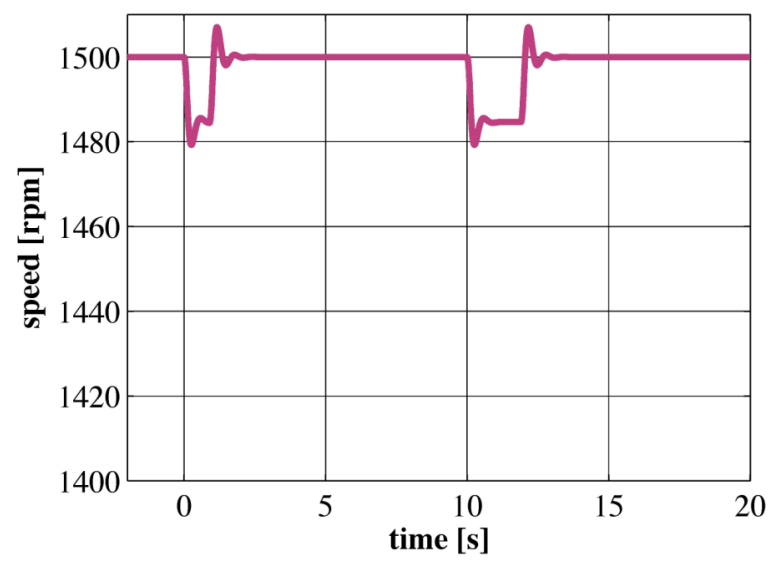

(a) Load impulses without rheostat, $R_{c}=0$

Fig. (12). Speed during periodic loading of the chipper drive.

To derive some general rules from Figs. (10-12) we now assume that stationary speed is not reached during the load impulse:

- In this case it is evident that current and torque peaks decrease with a short impulse length $\Delta t$.

- A larger inertia, however, will decrease current and torque peaks, as well as the speed dip, since the time constants of the transients increase.

- A larger rotor resistance will also decrease stator current and torque peaks, which gives also rise to decreased rotor current peaks.

\section{PARAMETER ESTIMATION FROM REAL MOTOR DATA}

In many cases the following parameters needed for the simulation of the drive are not available:

- $\quad$ stator resistance $R_{s}$

- $\quad$ stator stray reactance $X_{s \sigma}$

- $\quad$ magnetizing reactance $X_{m}$

- $\quad$ rotor stray reactance $X_{r \sigma}$

- $\quad$ rotor resistance $R_{r}$

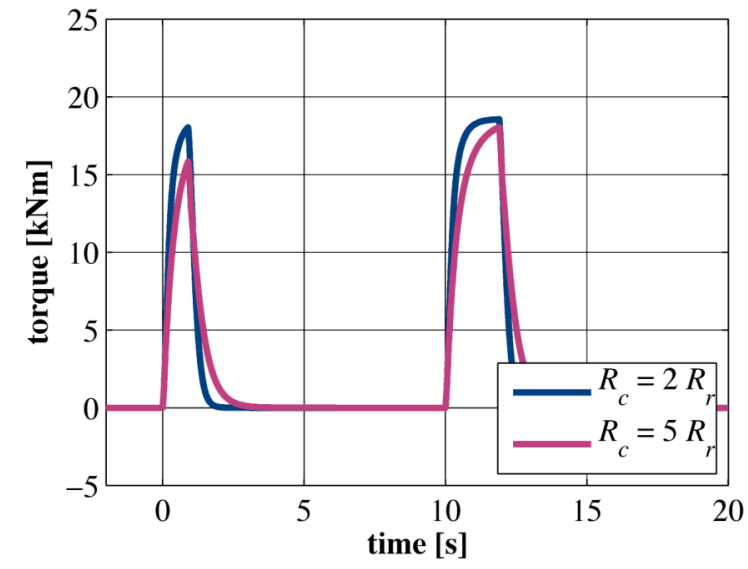

(b) Load impulses with $R_{c}=2 R_{r}$ and $R_{c}=5 R_{r}$

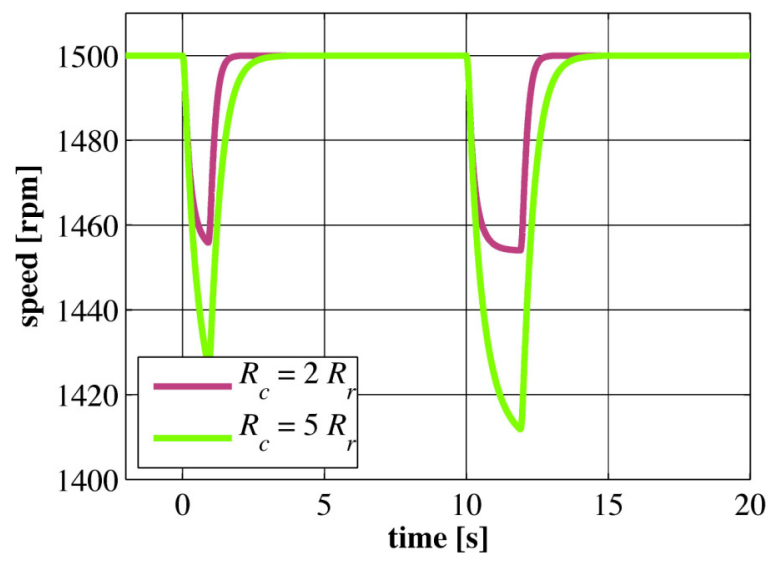

(b) Load impulses with $R_{c}=2 R_{r}$ and $R_{c}=5 R_{r}$

Resistances can be measured or are available from a series test report. The remaining reactances can be determined from motor data according to (Table 2), which are either given or which can be measured.

Table 2. Available Motor Data

\begin{tabular}{|c|c|}
\hline Parameter & Description \\
\hline \hline$p$ & number of pole pairs \\
\hline$P_{\text {nom }}$ & nominal power \\
\hline$V_{\text {nom }}$ & nominal stator phase voltage \\
\hline$f_{\text {nom }}$ & nominal supply frequency \\
\hline$I_{\text {nom }}$ & nominal stator phase current \\
\hline$n_{\text {nom }}$ & nominal speed \\
\hline$T_{\mathrm{bd}}$ & break down torque \\
\hline$I_{0}$ & no load stator phase current \\
\hline$V_{r, 0}$ & open circuit rotor phase voltage \\
\hline$R_{r}$ & rotor phase resistance \\
\hline
\end{tabular}


For the following investigation, however, the stator resistance is neglected. An approximation of the torque speed characteristic is given by the Kloss equation [3]:

$$
\frac{T}{T_{\mathrm{bd}}}=\frac{2}{s / s_{\mathrm{bd}}+s_{\mathrm{bd}} / s}
$$

The index bd refers to the break down (pull out) point of the induction motor. Kloss equation states a relation between the break down torque and slip and an arbitrary load point determined by torque $T$ and slip $s$. The nominal load torque of the motor can be determined from the mechanical power and speed:

$$
T_{\text {nom }}=\frac{P_{\text {nom }}}{2 \pi n_{\text {nom }}}
$$

Nominal slip is calculated by:

$$
s_{\text {nom }}=\frac{f_{\text {nom }}-p n_{\text {nom }}}{f_{\text {nom }}}
$$

Since break down torque is usually available, break down slip can be determined from (5):

$$
\frac{S_{\text {bd }}}{S_{\text {nom }}}=\frac{T_{\text {bd }}}{T_{\text {nom }}}+\sqrt{\left(\frac{T_{\text {bd }}}{T_{\text {nom }}}\right)^{2}-1}
$$

The transformation ratio, $v$, of the ideal transformer in Fig. (4) can be determined from the open circuit rotor phase voltage, $V_{r, 0}$ at nominal voltage: $V_{r, 0}$

$v=\frac{V_{r, 0}}{X_{m} I_{0}}$.

Applying this ratio, the rotor leakage reactance and the rotor winding resistance can be transformed to the stator side Fig. (13):

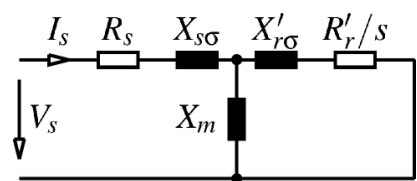

Fig. (13). Single phase equivalent circuit of a short circuited slip ring induction motor with rotor resistance and rotor reactance transformed to the stator side.

$X_{r \sigma}^{\prime}=v^{2} X_{r \sigma}$

$$
R_{r}^{\prime}=v^{2} R_{r}
$$

The motor impedance is:

$$
Z_{s}=\frac{\mathrm{j} X S\left(R_{r}^{\prime} / s+\mathrm{j} X_{r}^{\prime}\right)+X_{m}^{2}}{R_{r}^{\prime} / s+\mathrm{j} X_{r}^{\prime}}
$$

In this equation the stator and rotor reactances

$$
\begin{aligned}
& X_{s}=X_{m}+X_{s \sigma}, \\
& X_{r}^{\prime}=X_{m}+X_{r \sigma}^{\prime},
\end{aligned}
$$

are used. When introducing the leakage factor

$$
\sigma=1-\frac{X_{m}^{2}}{X_{s} X_{r}^{\prime}}
$$

and the break down slip

$S_{\mathrm{bd}}=\frac{R_{r}^{* \prime}}{\sigma X_{r}^{\prime}}$,

according to [3], and substituting the current for infinite slip $(s \rightarrow \infty)$

$$
I_{\infty}=\frac{V_{\text {nom }}}{\sigma X_{s}},
$$

we can determine an expression for the motor current at nominal voltage:

$\frac{I_{s}}{I_{\infty}}=\sqrt{\frac{\sigma^{2}+\left(s / s_{\mathrm{bd}}\right)^{2}}{1+\left(s / s_{\mathrm{bd}}\right)^{2}}}$.

Evaluating (18) for $s=0$ we find the no load current $I_{0}$

$\frac{I_{0}}{I_{\infty}}=\sigma$.

Evaluating (18) for $s=s_{\text {nom }}$ we obtain for the nominal current

$\frac{I_{\text {nom }}}{I_{\infty}}=\sqrt{\frac{\sigma^{2}+\left(s_{\text {nom }} / s_{b d}\right)^{2}}{1+\left(s_{\text {nom }} / s_{b d}\right)^{2}}}$.

Dividing (19) by (20), we find an equation for determining the leakage factor $\sigma$ :

$\frac{I_{0}}{I_{\infty}}=\sigma \sqrt{\frac{1+\left(s_{\text {nom }} / s_{b d}\right)^{2}}{\sigma^{2}+\left(s_{\text {nom }} / s_{b d}\right)^{2}}}$

with the solution:

$$
\frac{1}{\sigma^{2}}=\left(\frac{I_{\text {nom }}}{I_{0}}\right)^{2}+\left(\frac{I_{\text {nom }}}{I_{0}}\right)^{2}\left(\frac{s_{\text {bd }}}{s_{\text {nom }}}\right)^{2}-\left(\frac{s_{\text {bd }}}{s_{\text {nom }}}\right)^{2}
$$

From the no load current

$I_{0}=\frac{V_{\text {nom }}}{X_{s}}$

we can determine $X_{s}$.

Since the three phase stator and rotor windings are of similar construction, it sounds reasonable to partition the leakage reactances equally between stator and rotor which leads to $X_{r}^{\prime}=X_{s}$. Using (15), $X_{s}$ derived from (23) and $\sigma$ derived from (22), we are able to calculate the desired reactances:

$$
\begin{aligned}
& X_{m}=\sqrt{(1-\sigma) X_{s} X_{r}^{\prime}} \\
& X_{s \sigma}=X_{s}-X_{m} \\
& X_{r \sigma}^{\prime}=X_{r}^{\prime}-X_{m} .
\end{aligned}
$$




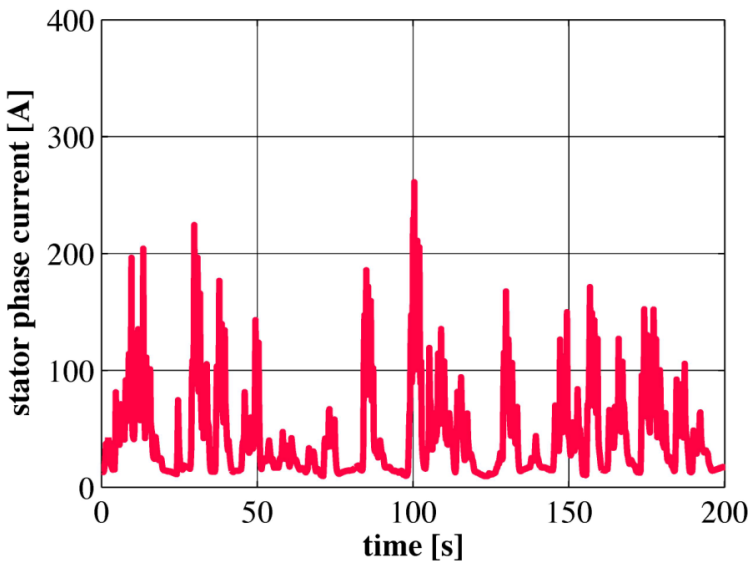

(a) Stator phase current versus time

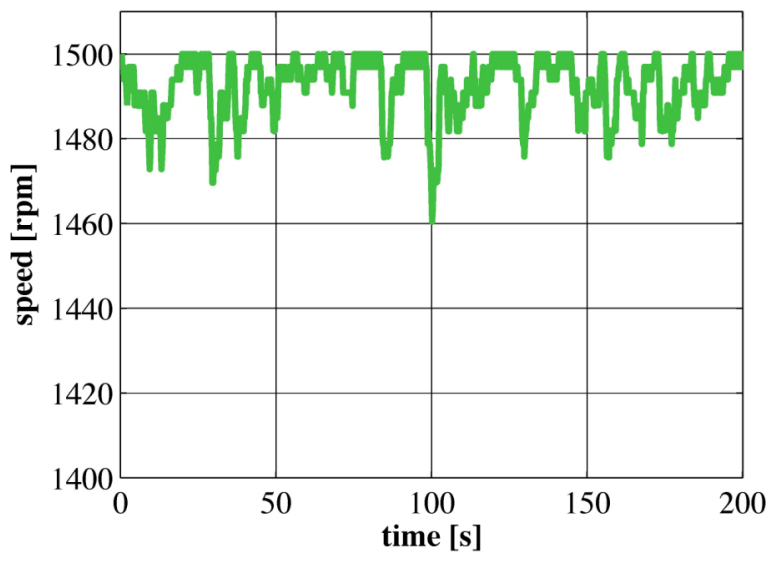

(b) Speed versus time

Fig. (14). Measurement results of a 1.5 MW four pole slip ring induction motor.

\section{PRACTICAL APPLICATION}

In a consulting project, a $6 \mathrm{kV}$ (line-to-line voltage), 1.5 MW four pole chipper drive was investigated. The nominal current of the motor was $165 \mathrm{~A}$. With the single phase pulse controlled rheostat, the motor was started using a time dependent control. The main problems of the chipper drive were unacceptable voltage sags as well as damages of the rotor windings due to high currents during heavy duty operation. The constant external rotor circuit resistance $R_{c}$ was only two times the rotor resistance $R$. Using the simulation model described in this paper, it was possible to show that this value was much too small for the actual drive load. Increasing the constant external rotor circuit resistance $R_{c}$ to five times the rotor resistance $R r$, gave rise to sufficiently reduced voltage sags. After improving the design of the connections from the rotor windings to the slip rings, and due to the reduced (rotor) current peaks, no more short circuit faults occurred.

Measurements obtained from the chipper drive during during heavy duty operation are depicted in Fig. (14). The comparison of the measurement results with the simulation results (Figs. (10-12) with $R_{c}=2 R_{r}$ ) show similar amplitudes of the current peaks and speed dips.

\section{CONCLUSIONS}

A simulation model of a slip ring induction motor operating in a chipper drive application is presented. The Modelica model of the chipper drive is used to investigate the impact of an external rotor resistance on the stationary and transient start-up as well as the transient effects due to load impulse. The simulation results show that a load impulses can be attenuated with an increased external rotor resistance. The simulation results are compared with the measurement results obtained from a consulting project. For measurement and simulation the current and speed curves show a good coincidence. For the consulting project it was therefore recommended to increase the external rotor resistance to reduce the current peaks of the chipper drive and voltage sags of the mains. In addition to that, an estimation technique for obtaining motor parameters from standard motor data is presented.

\section{REFERENCES}

[1] P.L. Alger, Induction Machines, New York: Gordon and Breach Science Verlag, 1970.

[2] P. Fritzson, Principles of Object-Oriented Modeling and Simulation with Modelica 2.1, Piscataway, NJ: IEEE Press, 2004.

[3] R. Fischer, Elektrische Maschinen, $5^{\text {th }}$ ed., München: C. Hanser Verlag, 1983. 